\title{
Management of hepatic metastases of well/moderately differentiated neuroendocrine tumors of the digestive tract
}

\author{
Anna La Salvia ${ }^{1}$, Stefano Partelli ${ }^{2}$, Marco Tampellini ${ }^{1}$, Domenico Tamburrino ${ }^{3}$, Massimo Falconi ${ }^{2}$, \\ Giorgio V. Scagliotti ${ }^{1}$, Maria Pia Brizzi ${ }^{1}$ \\ ${ }^{1}$ Division of Medical Oncology, Department of Oncology, University of Turin, San Luigi Gonzaga Hospital, Regione Gonzole 10, 10043 Orbassano, Italy. \\ ${ }^{2}$ Pancreatic Surgery Unit, San Raffaele Hospital, Vita-Salute San Raffaele University, 20132 Milan, Italy. \\ ${ }^{3}$ HPB Unit, Royal Free Hospital, London NW32QG, UK.
}

Correspondence to: Dr. Maria Pia Brizzi, Division of Medical Oncology, Department of Oncology, University of Turin, San Luigi Gonzaga Hospital, Regione Gonzole 10, 10043 Orbassano, Italy. E-mail: mariapia.brizzi@email.it

\section{A B S T R A C T}

In neuroendocrine tumors (NETs), liver metastases (LM) represent the most crucial prognostic factor, irrespective of the primary tumor site. At diagnosis, about $65-95 \%$ of gastroenteropancreatic neuroendocrine tumors (GEP-NETs) show hepatic metastasis. Management strategies of LM are heterogeneous and range from systemic therapy to liver-directed procedures. The type of systemic therapy used is dependent on the grade and proliferation of the tumor and includes somatostatin analogues, interferon, m-Tor and tyrosine kinase inhibitors, and chemotherapy. Angiographic liver-directed techniques, such as transarterial embolization/ chemoembolization and selective internal radiation therapy, offer excellent palliation for patients with liver-predominant disease. In highly selected cases, liver transplantation and peptide receptor radionuclide therapy are considered. The relatively low disease incidence and the diversity of presentation have led to a lack of well-conducted randomized controlled trials comparing the efficacy of different treatment options. Experience indicates that surgery is the only treatment that offers potential for cure. For unresectable lesions, the absence of data from rigorous trials limits the validity of many publications that detail management. In this review we will discuss the existing approaches for hepatic metastases from GEP-NETs.

Key words: Gastroenteropancreatic carcinoids; metastases; systemic treatment

\section{INTRODUCTION}

Neuroendocrine tumors (NETs) are rare neoplasms originating from diffuse neuroendocrine cells. Even though site of origin could sometimes be unknown, NETs frequently involve any part of the gastrointestinal tract (including endocrine pancreas), bronchopulmonary tree, thyroid, and thymus and have a wide range of malignant potential. The rapid evolution of clinical and pathological findings has hampered a systematic classification of this inhomogeneous family of tumors. The last World Health Organization (WHO) classification was published in 2010. ${ }^{[1]}$ Basically, NETs are classified according to tumor differentiation and site of occurrence. Highly aggressive, poorly differentiated neoplasms were defined as Grade-3 neuroendocrine carcinomas (NECs) when originating from the gastrointestinal tract, or as small- or large-cell NECs when appearing in the lung. ${ }^{[2]}$ Well- to moderately differentiated neuroendocrine neoplasms (WMD-NEN)

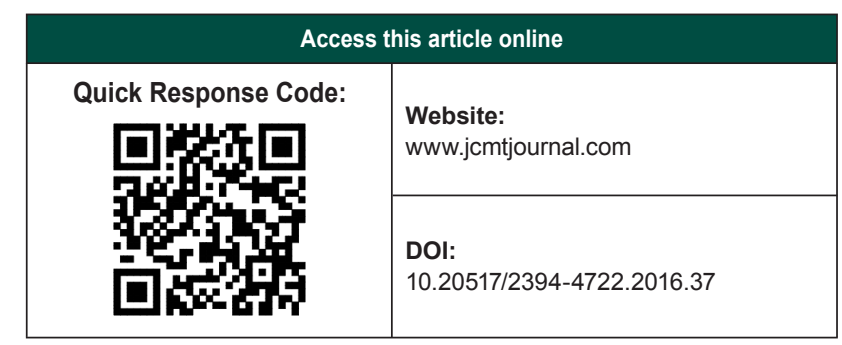

are a highly heterogeneous group of tumors comprising low-grade (G1) and intermediate-grade (G2) NETs of the gastrointestinal tract, typical and atypical carcinoids of the lung and thymus, and other cancers such as medullary thyroid carcinoma and pheochromocytoma/ paraganglioma. ${ }^{[1,2]}$ Finally, NETs could be associated with paraneoplastic syndromes or with a supranormal production of hormones responsible for specific syndromes.

The gastroenteropancreatic NETs (GEP-NETs) are the most common NETs. Due to their relatively indolent course, they are frequently diagnosed in an advanced stage ${ }^{[3,4]}$ with the development of liver metastases (LM) being the most frequent clinical occurrence. ${ }^{[3-5]}$ Metastatic spread to the liver may be accompanied by a wide spectrum of clinical presentations, from asymptomatic disease incidentally

This is an open access article distributed under the terms of the Creative Commons Attribution-NonCommercial-ShareAlike 3.0 License, which allows others to remix, tweak, and build upon the work non-commercially, as long as the author is credited and the new creations are licensed under the identical terms.

For reprints contact: service@oaepublish.com

How to cite this article: La Salvia A, Partelli S, Tampellini M, Tamburrino D, Falconi M, Scagliotti GV, Brizzi MP. Management of hepatic metastases of well/moderately differentiated neuroendocrine tumors of the digestive tract. J Cancer Metasta Treat 2016;2:294-303.

Received: 20-06-2016; Accepted: 18-07-2016. 
discovered during radiologic workup for other reasons, to debilitating symptoms caused by acid hypersecretion, serotonin syndrome, or carcinoid syndrome. In any case, the vast majority of patients with hepatic involvement will die of liver failure.

The management of patients with LM from GEP-NETs remains a matter of debate. It involves several specialties: surgery, medical oncology, radiotherapy, interventional radiology, and nuclear oncology. Despite the great number of options, there is no general consensus on the optimal treatment sequence in metastatic patients.

In this review, we focus on the most recent findings about management of LM from GEP-NETs.

\section{SURGERY}

Patients with pancreatic NETs frequently present with $\mathrm{LM}^{[6]}$ Treatment for LM includes a wide panel of treatments with the aim of achieving the best long-term result in overall survival (OS). NETs LM have been classified morphologically as type I (single metastasis), type II (isolated bulk metastasis accompanied by smaller deposits), or type III (disseminated metastatic spread). ${ }^{[7]}$ Surgery can play a role for type I LM, whereas medical treatment is always the treatment of choice for type III LM. ${ }^{[7,8]}$ The management of type II LM should be carefully evaluated, tailoring treatment to each individual patient. In metastatic pancreatic NETs (pNETs), 5-year survival rate is around $40-60 \% \cdot{ }^{[9-11]}$

Radical surgery, including resection of primary tumor and LM, improves survival rate up to $46-86 \%$ at 5 years and $35-79 \%$ at 10 years. ${ }^{[6,12,13]}$ Nevertheless, only $15-20 \%$ of patients with LM are suitable for radical resection due to the multifocality of the lesions or the inability to preserve an adequate amount of parenchyma following resection. ${ }^{[14]}$ Nowadays in referral centers, resections of up to $70 \%$ of total liver volume may be carried out with relatively low mortality rate $(0-5 \%)$ and acceptable morbidity $(30 \%){ }^{[15]}$ For surgery with curative intent, the European Neuroendocrine Tumor Society (ENETS) have proposed the following criteria: (1) resectable G1G2 liver disease with acceptable morbidity and less than $5 \%$ mortality; (2) absence of right heart insufficiency; (3) absence of unresectable lymph node and extra-abdominal metastases; (4) absence of diffuse or unresectable peritoneal carcinomatosis. ${ }^{[16]}$ Neuroendocrine carcinomas (NECs) that are G3 are usually not amenable to resection owing to their aggressive biology, high recurrence rates, and the consequent need to establish disease control. ${ }^{[17]}$ In the presence of unresectable metastatic disease, the role of debulking surgery (R2) is still controversial. In selected cases surgery may improve the quality of life or relief from symptoms when medical treatment has failed ${ }^{\left[{ }^{[18]}\right.}$ Several nonrandomized series have documented the benefits of either complete or cytoreductive surgical resection, compared with nonresectional treatment. They show a 74\% 5-year survival for resection, compared with $30 \%$ for angiographic techniques. The Cochrane systematic reviews ${ }^{[19,20]}$ did not identify benefit of liver resection, either in terms of complete resection (R0 or R1) or cytoreduction (R2). Despite poor data, surgery is the main treatment of choice because it is the only approach with intent to cure. Whether cytoreductive surgery $(90 \%$ resection) should be done when alternative nonsurgical treatment options are available is unknown. ${ }^{[8]}$

In case of bilateral liver disease, different surgical approaches can be performed, including a 2-staged liver resection. Another technical option is occlusion of the portal vein in the tumor-bearing liver lobe, either by radiological portal vein embolization than with surgical portal vein ligation before surgery. ${ }^{[21,22]}$

\section{LIVER TRANSPLANTATION (LT)}

In patients affected by NETs with unresectable LM, LT can be proposed due to the relatively low biological aggressiveness and slow growth of the majority of lowgrade NETs. In the last 15 years, short-term outcomes have improved because of better selection of transplantation candidates, refinement of surgical techniques, and the introduction of novel immunosuppressive regimens. Moving from their former experience with hepatocellular cancer, the Milan group observed improved outcomes of LT for NETs LM patients, prospectively applying strict inclusion criteria: (1) well-differentiated NETs (Ki67 < $5 \%$ ); (2) portosystemic tumor drainage; (3) patient age $<55$ years; (4) stable disease for at least 6 months; (5) pretransplant R0 primary tumor resection; (6) hepatic tumor involvement $<50 \%$ of total liver volume; and (7) absence of extrahepatic disease. ${ }^{[23]}$ The two largest retrospective multicenter studies have shown that in the absence of poor prognostic factors, LT is associated with satisfactory outcomes. In particular, a European multicenter study included a large retrospective cohort of 213 patients who underwent LT for NET LM from 1982 to 2009 . At a median follow-up of 56 months, $17 \%$ of patients died from early or late complications of LT, and the 5-year OS rate was $52 \%$ with a disease-specific survival rate of $30 \% .{ }^{[24]}$ A study from the United States included 85 patients who underwent LT from 1988 to 2012. One, three, and five-year survival rates were $83 \%, 60 \%$, and $52 \%$, respectively, and half of deaths were due to recurrent disease. Synchronous major primary tumor resections (i.e. pancreatoduodenectomy, small bowel resection with distal pancreatectomy, multivisceral transplant) appeared to contribute to worse outcomes. ${ }^{[25]}$ In other single-center series, the 5 -year OS rates ranged from $33 \%$ to $90 \%$, and disease-free survival rates ranged from $11 \%$ to $77 \%$ at 5 years. ${ }^{[26-29]}$ Despite these experiences, firm evidence on this issue is still scarce because only $0.3 \%$ and $0.2 \%$ of transplants are performed for such indications (data from the European Liver Transplant Registry and the United 
Network for Organ Sharing database. ${ }^{[30]}$ Moreover, the optimal timing of transplantation (e.g., whether stable disease needs to be observed for a certain amount of time) and selection criteria (including development of patientspecific biomarkers to identify those who gain a long-term benefit from the procedure) are still debated.

\section{THERMAL ABLATION (TA)}

The most widely applied TA modalities in the liver include radiofrequency (RF), microwave (MW), laser, cryoablation, and high-intensity focused ultrasonography. TA is often used alone or in conjunction with operative resection in the treatment of both primary and secondary hepatic malignancies. RF and MW ablation involves direct insertion of ablation probes into the region of a tumor, followed by application of several cycles of hyperthermic energy to induce cell death. MW ablation is thought to be more effective than RF ablation because a shorter time is needed for each ablation, and higher intratumor temperatures can be reached. Use of TA requires real-time ultrasonography guidance. The United States Food and Drug Administration has approved TA for the treatment of primary and metastatic tumors of the lung and liver. ${ }^{[31]}$

RF ablation has been used for relief of symptoms of hepatic metastases of insulin- or serotonin-secreting NETs ${ }^{[32]}$ and favorable 5-year survival rates after liver resection. ${ }^{[33]}$ More than a dozen lesions can be treated in a single patient, and many patients tolerated repeated ablations for recurrent disease. ${ }^{[33]}$ To date, no randomized trials have been undertaken to study whether surgical techniques such as liver resection and/or RF ablation are more effective than hepatic artery embolization or radio embolization, peptide receptor radionuclide therapy (PRRT), or medical systemic treatments in patients with NET and LM.

\section{PERCUTANEOUS LIVER- DIRECTED TECHNIQUES WITH A CYTOREDUCTIVE AIM}

In NET patients with liver disease only or with liverdominant metastases, loco-regional approaches such as ablative techniques or intra-arterial therapies can be proposed in place of upfront surgery with a cytoreductive aim, leading to lesion resectability and a 5-year survival rate of $50 \% \cdot{ }^{[34-36]}$

In particular, it is well known that NET hepatic metastases are characterized by a high rate of vascularization, as opposed to many other liver primary or secondary malignancies. Vascularization of NETs LM depends mostly on the hepatic artery, whereas normal liver parenchyma has a unique dual blood supply from both the proper hepatic artery $(20-40 \%)$ and the portal vein $(60-80 \%) .{ }^{[37]}$

Arterially directed interventional strategies, such as transarterial embolization (TAE) and transarterial chemoembolization (TACE) with a radiologically controlled percutaneous technique have been widely investigated and adopted during the past decade for the treatment of NETs LM. These strategies have generated encouraging outcomes in term of survival, response, and quality of life. ${ }^{[38]}$ Indications included well-differentiated or moderately well-differentiated (Grade 1 or 2) unresectable symptomatic liver lesions (due to tumor bulk), excessive hormone production, and rapid progression of liver disease ${ }^{[39]}$ Hepatic TAE, usually performed using lipiodol, obtains ischemia and necrosis of neoplastic cells by selective catheterization and obstruction of the hepatic artery supplying tumor lesions. ${ }^{[40]}$ On radiologic evaluation, TAE has been shown to improve biophysical markers, palliate symptoms, and shrink tumor lesions. ${ }^{[41]}$ In contrast to TAE, TACE combines blockage of the tumor blood supply with intra-arterial administration of cytotoxic drugs. In clinical practice, TACE is preferred over TAE in patients with NET with the worst prognostic factors, such as foregut origin (lung or pancreas) and poorly differentiated NETs. ${ }^{[42]}$ Several different chemotherapeutic agents have been used in this setting (doxorubicin, streptozotocin, gemcitabine, mitomycin $\mathrm{C}, 5-\mathrm{FU}$, or cisplatin) along with either a transient or permanent embolic agent like ethiodized oil or lipiodol. ${ }^{[43]}$ This treatment has shown effective results in patients with metastatic liver disease, with reported OS values of 3-4 years and objective response of about $75 \%$. Notably, response to TACE is higher when treatment is used as a first-line therapy and liver involvement is lower. Combining results obtained with TAE and TACE, the rates of symptomatic responses ranged from 39 to $95 \%{ }^{[44-47]}$

An accurate multicentric retrospective review on 100 patients with NETs LM who submitted to TACE $(n=49)$ or TAE $(n=51)$ showed comparable rates of symptom control ( $88 \%$ vs. $83 \%$, respectively), similar toxicities, and comparable survival outcomes (median OS: 25.7 vs. 25.5 months, respectively). These data suggest that the two techniques should be considered comparable. ${ }^{[48]}$ Future trials focusing on the evaluation of either the efficacy of different intra-arterial techniques or the role of a combination of loco-regional approaches with systemic therapies are needed.

\section{SELECTIVE INTERNAL RADIOTHERAPY (SIRT)}

Percutaneous angiographic techniques should be used in patients with Grade 1 or 2 tumors who have liverpredominant disease. The best treatment effect is achieved in patients with $<50 \%$ hepatic involvement and no extrahepatic disease. SIRT is a targeted approach that delivers glass or resin microspheres labeled with $90 \mathrm{Yttrium}$ (Y-90) that is primarily a beta particle emitter. Y-90 hepatic arterial administration is emerging as a promising treatment modality in the management of NETs patients with LM. ${ }^{[49,50]}$ Down-sizing/down-staging of hepatic tumors as a bridge to subsequent surgical treatment 
appears promising. Even though Y-90 radio-embolization may achieve a survival benefit, especially in patients presenting with significant tumor shrinkage, however, this technique is not easily available, especially in outlying hospitals. ${ }^{[51]}$

Long-term outcome analysis after SIRT indicated treatment response in $62.7 \%$ of the patients, disease stabilization in $32.5 \%$, and a survival rate of $45.0 \%$ at 3 years. Findings from an international multicenter prospective treatment registry showed that safety and response rates of SIRT and TACE were similar when evaluated at 6 months. ${ }^{[52]}$ At 12 months, the group receiving SIRT had a significantly lower response rate than the group receiving TACE $\left(46 \%\right.$ vs. 66\%). ${ }^{[46]}$ It should be noted that portal vein thrombosis and impaired liver function are not considered contraindications to SIRT, as they are for TACE and TA. Adverse events associated with SIRT included lung shunting of beads, radiation gastritis, duodenal ulceration, and hepatic fibrosis. Finally, the SIRT procedure is not considered pharmaco-economically advantageous. ${ }^{[53]}$

\section{PRRT}

PRRT is a form of molecular targeted therapy which uses a small peptide (a somatostatin analog similar to octreotide) coupled with a radionuclide emitting beta radiation. This therapy can be proposed only to patients with somatostatin receptor expressing NETs. In phase II studies PRRT was demonstrated to obtain objective response rates in 20-35\% of treated patients. ${ }^{[54-57]}$ Thus, it could have a potential role as a cytoreductive preoperative therapy, as demonstrated by several case reports in patients with GEP-NETs. ${ }^{[55-57]}$ The most important positive predictive factor for response to PRRT was the ratio of radiolabel uptake on diagnostic scans (normal to tumor). In a retrospective analysis, complete and partial tumor remission was reported in $2 \%$ and $28 \%$ of 310 patients, respectively, who received 177Lu-DOTATATE treatment for various histologic types of metastasized NETs. ${ }^{[58]}$ Of those patients, $89 \%$ had hepatic metastases, with extensive and moderate liver involvement in $27 \%$ and $62 \%$, respectively. The median time to progression was 40 months, and the median OS from the first treatment cycle was 46 months. The OS from initial diagnosis was 128 months, yielding a survival benefit of 40 to 72 months compared with historical cohorts. ${ }^{[58]}$ Extensive hepatic metastatic involvement is a significant negative predictive factor for progression-free survival (PFS) or OS with PRRT. ${ }^{[58]}$ A phase- 3 trial comparing PRRT and octreotide was presented at the 2015 18th-ECCO-40thESMO Congress. ${ }^{[59]}$ In this first prospective randomized study in patients with progressive metastatic midgut NETs, 177Lu-DOTATATE was superior to octreotide $60 \mathrm{mg}$ in terms of PFS (not reached vs. 8.4 months, $P<0.0001$ ) and overall response rate $(19 \%$ vs. $3 \%, P<0.0004)$. Interim analysis suggests increased OS (13 vs. 22 deaths), to be confirmed by final analysis. The combination of PRRT with radiosensitizing chemotherapy has been considered a promising strategy to enhance resectability of metastatic lesions. ${ }^{[60]} 5$-FU or capecitabine has been used in many of the numerous trials investigating the effects of external beam radiotherapy with chemotherapy. Also, Y-90 labeled antibody radioimmunotherapy in combination with 5-FU as radiosensitizer was found to be feasible and safe. ${ }^{[18]}$ The combination therapy of PRRT and oral everolimus was less effective than 177-Lu-DOTATATE only in the rat pancreatic CA20948 tumor model. ${ }^{[61]}$ Despite the low toxicity, a caveat is the limited access to this therapy in Europe, the USA, and Japan. Rare side effects of treatment can adversely affect the kidney and bone marrow.

\section{SYSTEMIC TREATMENT}

\section{Immunotherapy}

A potential role of interferon alpha (IFN $\alpha$ ) has been explored in several studies: an older comprehensive review reported an overall response rate of $20 \%$, ${ }^{[62]}$ whereas some small-sized retrospective and randomized trials have reported an improvement of PFS and OS. ${ }^{[63-65]}$ However, these benefits in outcome were not confirmed in other studies. ${ }^{[6]}$ The combination of IFN $\alpha$ with continuous infusion of 5-fluorouracil was explored in a phase-II study of patients with rapidly progressive NETs, and an overall response rate of 41.6 was achieved. ${ }^{[67]}$ Other studies enrolling limited patient series have demonstrated the role of immunotherapy/immunochemotherapy in obtaining a significant shrinkage of LM from NETs. ${ }^{[68-70]}$ However, further investigations are needed to better define whether immunotherapy or immunochemotherapy could have a role as a neoadjuvant strategy in NETs.

\section{Biotherapy}

In well- and moderately differentiated somatostatin receptor expressing NETs, the mainstay of treatment consists of somatostatin analogue (SSA) administration, made manageable with long-acting repeatable (LAR) formulations. ${ }^{[71]}$ Therapy with SSAs represents the standard of care in patients with metastasized, nonresectable midgut NETs, pancreatic NETs, or NETs of unknown origin, whether associated or not with hormone hypersecretion and regardless of the hepatic tumor burden. Randomized phase-III, multicenter trials demonstrated that LAR octreotide and lanreotide depot can significantly prolong PFS in a heterogeneous population of patients with GEP-NETs. ${ }^{[72,73]}$ Therapy with SSAs, however, did not demonstrate reduction of tumor load. The best clinical response obtained in all these studies was disease stabilization.

PROMID trial enrolled 85 treatment-naive patients with well-differentiated G1 advanced midgut or unknown origin NETs, randomizing them to receive either placebo or intramuscular octreotide LAR every 4 weeks (Sandostatin $\mathrm{LAR}^{\mathrm{TM}}$ ). Patients treated with octreotide LAR presented a longer time to tumor progression (14.3 vs. 6 months) and a higher disease stabilization rate $(66.7 \%$ 
vs. 37.2\%). ${ }^{[72]}$ CLARINET trial, a double-blind, phase-III study, randomized 204 patients with well- or moderately differentiated, Octreoscan-positive, nonfunctioning GEPNETs to receive lanreotide depot $120 \mathrm{mg}$ monthly versus placebo. SSAs therapy obtained a significant improvement in PFS, with a median time not reached in the experimental arm versus 18 months in the placebo group. The estimated rates of PFS at 24 months were $65.1 \%$ in the lanreotide group and $33 \%$ in the placebo group. No information on disease control rate was reported. ${ }^{[73]}$

Recently, the clinical activity of the new SSA pasireotide has been evaluated in an open-label, phase-II study enrolling advanced pancreatic and extrapancreatic Grade 1 and 2 NETs. ${ }^{[74]}$ Median PFS of the 29 treated patients was the primary endpoint of the study and was 11 months. According to the RECIST criteria, one patient obtained a partial response and 17 experienced disease stabilization, for a disease control rate of $64 \%$. In all the above-reported trials, treatment with SSAs resulted in low cytoreductive activity as demonstrated by the low objective response rates reported (around 5\%). This finding was recently confirmed in an extensive review. ${ }^{[75]}$ Thus, while SSAs can be considered the mainstay of treatment in well- or moderately well-differentiated NETs, both functioning or not, when a disease control is needed, there is no evidence to support the use of SSAs in the "neoadjuvant" setting.

\section{Targeted therapies}

Recently, novel targeted therapies such as everolimus and sunitinib have been introduced in the clinical management of G1 and G2 NETs.

Following exciting preclinical data demonstrating mTOR signaling pathway activation in NET cells, everolimus was extensively studied in cancer patients. ${ }^{[76-78]}$

Arandomized, phase-III, double-blind study (RADIANT-3) enrolled 410 patients with locally advanced or metastatic well- to moderately differentiated pancreatic NETs, comparing the PFS of patients treated with everolimus $10 \mathrm{mg} / \mathrm{day}$ to that of patients receiving placebo. The study met its primary endpoint as patients treated with everolimus presented a longer median PFS (11.0 vs. 4.6 months). Response rate was low, with only $5 \%$ of the patients randomized to receive everolimus achieving a partial response. ${ }^{[79]}$ Similar encouraging results have been obtained in the phase-III placebo-controlled RADIANT-2 study enrolling patients with well- and moderately differentiated locally advanced or metastatic NETs and carcinoid syndrome. Patients receiving everolimus plus SSA (octreotide LAR) presented a longer PFS than those treated with octreotide LAR plus placebo (16.4 vs. 11.3 months, $P=0.026$ ). Overall response rate was similar in both groups, with $2 \%$ of patients achieving a partial response and $82 \%$ disease stabilization. ${ }^{[80]}$ The advantages of treating patients with everolimus have recently been confirmed in a randomized, double-blind, placebo-controlled, phase-
III RADIANT-4 trial. The study evaluated everolimus efficacy in patients with advanced, well-differentiated NETs of different origin and with nonfunctional disease. Patients in the everolimus arm of the study presented a significant improvement in PFS (11.0 vs. 3.9 months). ${ }^{[81]}$ Interestingly, according to subgroup analysis, the positive treatment effect was confirmed irrespective of the extent of liver metastasis. Objective responses were recorded in four $(2 \%)$ patients receiving everolimus and in one patient (1\%) receiving placebo. Disease stabilization was the best overall response in 165 patients $(81 \%)$ in the everolimus group, compared with 62 patients $(64 \%)$ in the placebo group. The findings of these three studies were consistent with the role of everolimus in prolonging PFS and not in achieving tumor shrinkage. Thus, everolimus cannot be proposed as a preferred therapy in the neoadjuvant setting.

The activity of sunitinib, a multityrosine kinase inhibitor of vascular endothelial and platelet-derived growth factor receptors, was explored in a double-blind, placebocontrolled, phase-III trial enrolling 171 patients with advanced, well-differentiated progressing pancreatic NETs. ${ }^{[82]}$ The study met its primary endpoint, as median PFS of patients receiving sunitinib was significantly longer than that of patients treated with placebo (11.4 vs. 5.5 months). In contrast to what was observed in patients with renal cell carcinoma, ${ }^{[83]}$ tumor shrinkage rate in patients with pancreatic NET was low; only $9 \%$ of those treated with sunitinib achieved an objective response according to the RECIST criteria.

The high rate of vascularization of NETs led to initial interest in angiogenesis inhibition as a promising field of research. Furthermore, an overexpression of vascular endothelial growth factor (VEGF) has been observed in both carcinoid and p-NET (either in serum or in tissue), thus making VEGF and VEGFR excellent targets to be inhibited ${ }^{[84]}$ The anti-angiogenetic agent bevacizumab has been investigated combined with IFN $\alpha$ in a randomized phase-II trial of 44 patients with advanced (unresectable or metastatic) carcinoid tumors. Patients were randomized to receive 18 weeks of single agent bevacizumab or IFN. At disease progression or after 18 weeks of treatment, patients were allowed to receive the combination of these two treatments. The results obtained in the bevacizumab arm were encouraging; a partial response was achieved in $18 \%$ of the patients, with a better 18 -week PFS than in the IFN group (95\% vs. 67\%, respectively) ${ }^{[85]}$ However, even though bevacizumab monotherapy has been associated with improvement in response rate and survival, the results obtained in terms of tumor shrinkage were not encouraging, probably because of the cytostatic rather than cytotoxic effect of antiangiogenic therapies. Therefore, the role of bevacizumab-based combination therapy has been evaluated, mostly with chemotherapy agents or with mTOR inhibitors in the management of advanced GEPNETs. In the randomized phase-II study CALGB80701 (Alliance), patients with metastatic pNETs were randomly 
treated with everolimus or everolimus plus bevacizumab. The overall response rate was $31 \%$ and $12 \%$ for the combination treatment and everolimus alone, respectively. The current evidence from this available clinical trial suggests that combination strategy was more active but not more effective in terms of PFS. ${ }^{[86]}$

\section{Chemotherapy}

While chemotherapy is the standard of care for aggressive, poorly differentiated(G3), advanced, or metastatic NECs, ${ }^{[87]}$ it could represent a therapeutic option in symptomatic and progressive well- or moderately differentiated NETs. Notwithstanding a relatively high number of agents which have been demonstrated to be active in this latter tumor setting (platinum salts, 5-fluorouracil, doxorubicin, streptozotocin, temozolomide, and capecitabine), the best chemotherapeutic strategy remains controversial. ${ }^{[88]}$

As far as unresectable or metastatic pancreatic NETs are concerned, polychemotherapy was more active than monotherapy, with a response rate in this latter group lower than $20 \%$. A retrospective study evaluating the combination of streptozotocin (STZ) with doxorubicin and 5-fluorouracil (5-FU) reported a response rate of $39 \%$, with a median response duration of 9.3 months. The 2 -year PFS rate was $41 \%$, and the 2 -year OS rate was $74 \%$. Tumor burden clearly affected survival outcomes in both univariate and multivariate analyses. In fact, the PFS rate at 2 years for patients with LM involving $\leq 75 \%$ of the parenchyma was $41 \%$, whereas all 12 patients with LM involving more than $75 \%$ of the organ had experienced disease progression by 14.2 months $(P=0.01)$. At 2 years, the OS rate for patients with $\mathrm{LM} \leq 75 \%$ was $83 \%$, whereas all 12 patients with LM more than $75 \%$ had died at 15.5 months $(P=0.0001){ }^{[89]}$

The combination of temozolomide with capecitabine was demonstrated to be more active and better tolerated than STZ-based regimens. In a retrospective study enrolling metastatic pancreatic NETs, objective response rate of temozolomide combination was reported to be $70 \%$. It has to be noted, however, that in this study only $30 \%$ of the patients had moderately differentiated (G2) tumors. ${ }^{[90]}$ The combination of octreotide LAR $20 \mathrm{mg}$, metronomic capecitabine, and intravenous bevacizumab was explored in the XELBEVOCT phase-II study enrolling 45 patients with well- to moderately differentiated NETs from various primary origins (pancreas, intestinal tract, lungs, and unknown site). Objective response rate was $17.8 \%$ with a median PFS of 14.9 months. This study demonstrated that the combination of SSA plus capecitabine and bevacizumab was active and well tolerated in this group of patients. ${ }^{[91]}$

Finally, a retrospective study evaluated the combination of 5-fluorouracil, dacarbazine, and epirubicin in patients with well-differentiated NETs originating from pancreas, intestine, stomach, gallbladder, kidney, or an unknown site. Chemotherapy was well tolerated and outcome results were encouraging. Tumor shrinkage was obtained in 44\% of the patients, with a median duration of response of 12 months. Objective response rates recorded in pancreatic, gastrointestinal, and extradigestive NETs were 58\%, 25\%, and $36 \%$, respectively. Interestingly, disease control was achieved in $83 \%$ of the patients progressing at the time of study inclusion. Median PFS was 11 months and OS was 21 months. ${ }^{[92]}$

Notwithstanding this body of evidence, the number of patients enrolled in each study was relatively low, thus preventing any definitive conclusion on which could be the best chemotherapeutic strategy for each subset of patients. New multicenter, well designed, randomized clinical trials are needed.

\section{CONCLUSION}

About one in seven patients diagnosed with digestive NETs presents with metastatic disease at the time of diagnosis, with the liver being the most frequently involved organ. Moreover, $25 \%$ to $90 \%$ of patients who are nonmetastatic at diagnosis are expected to develop metastases during the course of the disease. In clinical practice, hepatic failure represents the primary cause of death in these patients. Surgery is the only technique that may permit curability of liver involvement. Thus, all treatments should primarily be focused on tumor shrinkage, especially when unresectable liver lesions could become resectable if reduced in size. When complete resection is not possible, treatment goals should be tumor control and symptom relief.

Complete resection of primary and metastatic disease (when possible) and surgical debulking of symptomatic diseases are standard procedures for G1 and G2 NETs. To patients with Grade 1 or 2 NETs (either pNETs or gastrointestinal NETs) with LM and without extra-abdominal metastasis and peritoneal carcinomatosis, surgery permits the best results in terms of recurrence-free survival and outcome. Unfortunately only $10-25 \%$ of patients can be directly submitted to surgical resection. These considerations suggest that "neoadjuvant strategies" should be explored in patients with liver-confined metastatic disease. Despite the proven efficacy of different systemic treatment strategies for metastatic NETs (SSAs, PRRT, chemotherapy, or target therapies such as everolimus, sunitinib, and bevacizumab), none of these approaches resulted in significant tumor shrinkage. Few studies have explored systemic therapies in the neoadjuvant setting. Unfortunately, trial designs, inhomogeneous inclusion and exclusion criteria, and the relatively low number of patients have hampered definitive conclusions in this patient setting.

Further research is needed to determine the value of these medical treatments as a cytoreductive strategy against LM from NETs. Moreover, loco-regional approaches to LM, such as radiofrequency ablation, laser ablation, or intra- 
arterial therapies (embolization/chemoembolization), may be useful in reducing tumor burden only in selected cases. Application of the concept of tumor response as defined by RECIST or WHO criteria in patients with metastatic NETs is worthy of mention. Often it is difficult to select the target lesions to be monitored over time. Furthermore, necrosis or hemorrhage within other clinical occurrences may be misinterpreted as a stable disease instead of a response.

In conclusion, while surgical management of resectable LM from NETs is a standardized procedure, there is no consensus on the best therapeutic strategy for all other patients. For example, it is a matter of debate whether incomplete surgical resection of bulky but asymptomatic metastasis from NETs is preferable to systemic biotherapy. Extremely promising recent data have been reported in the Radiant 4 trial, suggesting that novel therapies (in particular the mTOR inhibitor everolimus) will play an increasingly important role in the management of advanced LM irrespective of the extent of liver metastasis.

Large prospective studies are needed to evaluate the optimal management of hepatic metastases from NETs, defining common guidelines and allowing the choice of the best treatment strategy for each individual patient.

\section{Financial support and sponsorship} Nil.

\section{Conflicts of interest}

There are no conflicts of interest.

\section{REFERENCES}

1. Mayo SC, de Jong MC, Bloomston M, Pulitano C, Clary BM, Reddy SK, Clark Gamblin T, Celinski SA, Kooby DA, Staley CA, Stokes JB, Chu CK, Arrese D, Ferrero A, Schulick RD, Choti MA, Geschwind JF, Strub J, Bauer TW, Adams RB, Aldrighetti L, Mentha G, Capussotti L, Pawlik TM. Surgery versus intraarterial therapy for neuroendocrine liver metastasis: a multicenter international analysis. Ann Surg Oncol 2011;18:3657-65.

2. Bosman FT, Carneiro F, Hruban RH, Theise ND. World Health Organization (WHO) Classification of Tumours of the Digestive System. 4th ed. Geneva, Switzerland: WHO Press; 2010.

3. Steinmuller T, Kianmanesh R, Falconi M, Scarpa A, Taal B, Kwekkeboom DJ, Steinmüller T, Taal B, Lopes JM, Perren A, Nikou G, Yao J, Delle Fave GF, O'Toole D; Frascati ConsensusConference participants. Consensus guidelines for the management of patients with liver metastases from digestive (neuro)-endocrine tumors: foregut, midgut, hindgut, and unknown primary. Neuroendocrinology 2008;87:47-62.

4. Alagusundaramoorthy SS, Gedaly R. Role of surgery and transplantation in the treatment of hepatic metastases from neuroendocrine tumor. World J Gastroenterol 2014;20:14348-58.

5. Kennedy A, Bester L, Salem R, Sharma RA, Parks RW, Ruszniewski P; NET-Liver-Metastases Consensus Conference. Role of hepatic intra-arterial therapies in metastatic neuroendocrine tumours (NET): guidelines from the NET-Liver-Metastases Consensus Conference. HPB (Oxford) 2015;17:29-37.

6. John BJ, Davidson BR. Treatment options for unresectable neuroendocrine liver metastases. Expert Rev Gastroenterol Hepatol
2012;6:357-69.

7. Frilling A, Li J, Malamutmann E, Schmid KW, Bockisch A, Broelsch CE. Treatment of liver metastases from neuroendocrine tumours in relation to the extent of hepatic disease. Br J Surg 2009;96:175-84.

8. Frilling A, Modlin IM, Kidd M, Russell C, Breitenstein S, Salem R, Kwekkeboom D, Lau WY, Klersy C, Vilgrain V, Davidson B, Siegler M, Caplin M, Solcia E, Schilsky R; Working Group on Neuroendocrine Liver Metastases. Recommendations for management of patients with neuroendocrine liver metastases. Lancet Oncol 2014;15:e8-21.

9. García-Carbonero R, Capdevila J, Crespo- Herrero G, Díaz-Pérez JA, Martínez Del Prado MP, Alonso Orduña V, Sevilla-García I, Villabona-Artero C, Beguiristain-Gómez A, Llanos-Muñoz M, Marazuela M, Alvarez-Escola C, Castellano D, Vilar E, JiménezFonseca P, Teulé A, Sastre-Valera J, Benavent-Viñuelas M, Monleon A, Salazar R. Incidence, patterns of care and prognostic factors for outcome of gastroenteropancreatic neuroendocrine tumors (GEP-NETs): results from the National Cancer Registry of Spain (RGETNE). Ann Oncol 2010;21:1794-803.

10. Ekeblad S, Skogseid B, Dunder K, Oberg K, Eriksson B. Prognostic factors and survival in 324 patients with pancreatic endocrine tumortreated at a single institution. Clin Cancer Res 2008;14:7798-803.

11. Bettini R, Boninsegna L, Mantovani W, Capelli P, Bassi C, Pederzoli P, Delle Fave GF, Panzuto F, Scarpa A, Falconi M. Prognostic factors at diagnosis and value of WHO classification in a monoinstitutional series of 180 non-functioning pancreatic endocrine tumours. Ann Oncol 2008;19:903-8.

12. Khasraw M, Gill A, Harrington T, Pavlakis N, Modlin I. Management of advanced neuroendocrine tumors with hepatic metastasis. $J$ Clin Gastroenterol 2009;43:838-47.

13. Mayo SC, de Jong MC, Pulitano C, Clary BM, Reddy SK, Gamblin TC, Celinksi SA, Kooby DA, Staley CA, Stokes JB, Chu CK, Ferrero A, Schulick RD, Choti MA,Mentha G, Strub J, Bauer TW, Adams RB, Aldrighetti L, Capussotti L, Pawlik TM. Surgical management of hepatic neuroendocrine tumor metastasis: results from an international multi-institutional analysis. Ann Surg Oncol 2010;17:3129-36.

14. Jaeck D, Oussoultzoglou E, Bachellier P, Lemarque P, Weber JC, Nakano H, Wolf P. Hepatic metastases of gastroenteropancreatic neuroendocrine tumors: safe hepatic surgery. World $J$ Surg 2001;25:689-92.

15. Yigitler C, Farges O, Kianmanesh R, Regimbeau J, Abdalla E, Belghiti J. The small remnant liver after major liver resection: how common and how relevant? Liver Transpl 2003;9:S18-25.

16. Pavel M, Baudin E, Couvelard A, Krenning E, Öberg K, Steinmüller T, Anlauf M, Wiedenmann B, Salazar R; Barcelona Consensus Conference participants. ENETS Consensus Guidelines for the management of patients with liver and other distant metastases from neuroendocrine neoplasms of foregut, midgut, hindgut, and unknown primary. Neuroendocrinology 2012;95:157-76.

17. Fazio N, Spada F, Giovannini M. Chemotherapy in gastroenteropancreatic (GEP) neuroendocrine carcinomas (NEC): a critical view. Cancer Treat Rev 2013;39:270-4.

18. Sarmiento JM, Que FG. Hepatic surgery for metastases from neuroendocrine tumors. Surg Oncol Clin N Am 2003;12:231-42.

19. Gurusamy KS, Ramamoorthy R, Sharma D, Davidson BR. Liver resection versus other treatments for neuroendocrine tumours in patients with resectable liver metastases. Cochrane Database Syst Rev 2009; doi: 10.1002/14651858.CD007060.pub2.

20. Gurusamy KS, Pamecha V, Sharma D, Davidson BR. Palliative cytoreductive surgery versus other palliative treatments in patients with unresectable liver metastases from gastro-entero-pancreatic neuroendocrine tumours. Cochrane Database Syst Rev 2009; doi: 10.1002/14651858.CD007118.pub2.

21. Kianmanesh R, Sauvanet A, Hentic O, Couvelard A, Lévy P, Vilgrain V, Ruszniewski P, Belghiti J. Two-step surgery for synchronous 
bilobar liver metastases from digestive endocrine tumors: a safe approach for radical resection. Ann Surg 2008;247:659-65.

22. Schnitzbauer AA, Lang SA, Goessmann H, Nadalin S, Baumgart J, Farkas SA, Fichtner-Feigl S, Lorf T, Goralcyk A, Hörbelt R, Kroemer A, Loss M, Rümmele P, Scherer MN, Padberg W, Königsrainer A, Lang H, Obed A, Schlitt HJ. Right portal vein ligation combined with in situ splitting induces rapid left lateral liver lobe hypertrophy enabling 2-staged extended right hepatic resectionin small-for-size settings. Ann Surg 2012;255:405-14.

23. Coppa J, Pulvirenti A, Schiavo M, Romito R, Collini P, Di Bartolomeo M, Fabbri A, Regalia E, Mazzaferro V. Resection versus transplantation for liver metastases from neuroendocrine tumors. Transpantl Proc 2001;33:1537-9.

24. Le Treut YP, Gregoire E, Klempnauer J, Belghiti J, Jouve E, Lerut J, Castaing D, Soubrane O, Boillot O, Mantion G, Homayounfar K, Bustamante M, Azoulay D, Wolf P, Krawczyk M, Pascher A, Suc B, Chiche L, de Urbina JO, Mejzlik V, Pascual M, Lodge JP, Gruttadauria S, Paye F, Pruvot FR, Thorban S, Foss A, Adam R; For ELITA. Liver transplantation for neuroendocrine tumors in Europeresults and trends in patient selection: a 213-case European Liver Transplant Registry study. Ann Surg 2013;257:807-15.

25. Sher LS, Levi DM, Wecsler JS, Lo M, Petrovic LM, Groshen S, Ji L, Uso TD, Tector AJ, Hamilton AS, Marsh JW, Schwartz ME. Liver transplantation for metastatic neuroendocrine tumors: outcomes and prognostic variables. J Surg Oncol 2015;112:125-32.

26. Bonaccorsi-Riani E, Apestegui C, Jouret-Mourin A, Sempoux C, Goffette P, Ciccarelli O, Borbath I, Hubert C, Gigot JF, Hassoun Z, Lerut J. Liver transplantation and neuroendocrine tumors: lessons from a single centre experience and from the literature review. Transpl Int 2010;23:668-78.

27. Frilling A, Malago M, Weber F, Paul A, Nadalin S, Sotiropoulos GC, Cicinnati V, Beckebaum S, Bockisch A, Mueller-Brand J, Hofmann M, Schmid KW, Gerken G,Broelsch CE. Liver transplantation for patients with metastatic endocrine tumors: single-center experience with 15 patients. Liver Transpl 2006;12:1089-96.

28. Florman S, Toure B, Kim L, Gondolesi G, Roayaie S, Krieger N, Fishbein T, Emre S, Miller C, Schwartz M. Liver transplantation for neuroendocrine tumors. J Gastrointest Surg 2004;8:208-12.

29. Rosenau J, Bahr MJ, von Wasielewski R, Mengel M, Schmidt HH, Nashan B, Lang H, Klempnauer J, Manns MP, Boeker KH. Ki67, E-cadherin, and p53 as prognostic indicators of long-term outcome after liver transplantation for metastatic neuroendocrine tumors. Transplantation 2002;73:386-94.

30. Gedaly R, Daily MF, Davenport D, McHugh PP, Koch A, Angulo P, Hundley JC. Liver transplantation for the treatment of liver metastases from neuroendocrine tumors: an analysis of the UNOS database. Arch Surg 2011;146:953-8.

31. Steward MJ, Warbey VS, Malhotra A, Caplin ME, Buscombe JR, $\mathrm{Yu}$ D. Neuroendocrine tumors: role of interventional radiology in therapy. Radiographics 2008;28:1131-45.

32. Henn AR, Levine EA, McNulty W, Zagoria RJ. Percutaneous radiofrequency ablation of hepatic metastases for symptomatic relief of neuroendocrine syndromes. AJR Am J Roentgenol 2003;181:1005-10.

33. Norlén O, Stålberg P, Zedenius J, Hellman P. Outcome after resection and radiofrequency ablation of liver metastases from small intestinal neuroendocrine tumours. Br J Surg 2013; 100:1505-14.

34. Ho AS, Picus J, Darcy MD, Tan B, Gould JE, Pilgram TK, Brown DB. Roentgenol Long-term outcome after chemoembolization and embolization of hepatic metastatic lesions from neuroendocrine tumors. AJR Am J Roentgenol 2007;188:1201-7.

35. Osborne DA, Zervos EE, Strosberg J, Boe BA, Malafa M, Rosemurgy AS, Yeatman TJ, Carey L, Duhaine L, Kvols LK. Improved outcome with cytoreduction versus embolization for symptomatic hepatic metastases of carcinoid and neuroendocrine tumors. Ann Surg Oncol 2006; 13:572-81.

36. Touzios JG, Kiely JM, Pitt SC, Rilling WS, Quebbeman EJ, Wilson
SD, Pitt HA. Neuroendocrine hepatic metastases: does aggressive management improve survival? Ann Surg 2005;241:776-83; discussion 783-5.

37. Vogl TJ, Naguib NN, Zangos S, Eichler K, Hedayati A, Nour-Eldin NE. Liver metastases of neuroendocrine carcinomas: interventional treatment via transarterial embolization, chemoembolization and thermal ablation. Eur J Radiol 2009;72:517-28.

38. Toumpanakis C, Meyer T, Caplin ME. Cytotoxic treatment including embolization/chemoembolization for neuroendocrine tumours. Best Pract Res Clin Endocrinol Metab 2007;21:131-44.

39. Madoff DC, Gupta S, Ahrar K, Murthy R, Yao JC. Update on the management of neuroendocrine hepatic metastases. J Vasc Interv Radiol 2006;17:1235-49.

40. Del Prete M, Fiore F, Modica R, Marotta V, Marciello F, Ramundo V, Di Sarno A, Carratù A, De Luca di Roseto C, Tafuto S, Tatangelo F, Baldelli R, Colao A, Faggiano A, on the behalf of the Multidisciplinary Group for NeuroEndocrine Tumors of Naples. Hepatic arterial embolization in patients with neuroendocrine tumors. J Exp Clin Cancer Res 2014;33:43.

41. Carrasco CH, Charnsangavej C, Ajani J, Samaan NA, Richli W, Wallace $\mathrm{S}$. The carcinoid syndrome: palliation by hepatic artery embolization. AJR Am J Roentgenol 1986;147:149-54.

42. Pericleous M, Caplin ME, Tsochatzis E, Yu D, Morgan-rowe L and Toumpanakis C. Hepatic artery embolization in advanced neuroendocrine tumors: efficacy and long-term outcomes. Asia Pac J Clin Oncol 2016;12:61-9.

43. Kim YH, Ajani JA, Carrasco CH, Dumas P, Richli W, Lawrence D, Chuang V, Wallace S. Selective hepatic arterial chemoembolization for liver metastases in patients with carcinoid tumor or islet cell carcinoma. Cancer Invest 1999;17:474-8.

44. Kennedy A, Bester L, Salem R, Sharma RA, Parks R, Ruszniewski P, NET-Liver-Metastases Consensus Conference. Role of hepatic intra-arterial therapies in metastatic neuroendocrine tumours (NET): guidelines from the NET-Liver-Metastases Consensus Conference. HPB (Oxford) 2015;17:29-37.

45. Gupta S, Johnson MM, Murthy R, Ahrar K, Wallace MJ, Madoff DC, McRae SE, Hicks ME, Rao S, Vauthey JN, Ajani JA, Yao JC. Hepatic arterial embolization and chemoembolization for the treatment of patients with metastatic neuroendocrine tumors: variables affecting response rates and survival. Cancer 2005;104:1590-602.

46. Schell SR, Camp ER, Caridi JG, Hawkins IF Jr. Hepatic artery embolization for control of symptoms, octreotide requirements, and tumor progression in metastatic carcinoid tumors. $J$ Gastrointest Surg 2002;6:664-70.

47. Dong XD, Carr BI. Hepatic artery chemoembolization for the treatment of liver metastases from neuroendocrine tumors: a longterm follow-up in 123 patients. Med Oncol 2011;28 suppl 1:S286-90.

48. Pitt SC, Knuth J, Keily JM, McDermott JC, Weber SM, Chen H, Rilling WS, Quebbeman EJ, Agarwal DM, Pitt HA. Hepatic neuroendocrine metastases: chemo- or bland embolization? $J$ Gastrointest Surg 2008;12:1951-60.

49. Kennedy AS, Dezarn WA, McNeillie P, Coldwell D, Nutting C, Carter D, Murthy R, Rose S, Warner RR, Liu D, Palmedo H, Overton C, Jones B, Salem R. Radioembolization for unresectable neuroendocrine hepatic metastases using resin 90Y-microspheres: early results in 148 patients. Am J Clin Oncol 2008;31:271-9.

50. King J, Quinn R, Glenn D, Janssen J, Tong D, Liaw W, Morris DL. Radioembolization with selective internal radiation microspheres for neuroendocrine liver metastases. Cancer 2008;113:921-9.

51. Whitney R, Valek V, Fages JF, Garcia A, Narayanan G, Tatum C, Hahl M, Martin RC 2nd. Transarterial chemoembolization and selective internal radiation for the treatment of patients with metastatic neuroendocrine tumors: a comparison of efficacy and cost. Oncologist 2011;16:594-601.

52. Crowder CD, Grabowski C, Inampudi S, Sielaff T, Sherman CA, Batts KP. Selective internal radiation therapy-induced extrahepatic 
injury: an emerging cause of iatrogenic organ damage. Am J Surg Pathol 2009;33:963-75.

53. Kalinowski M, Dressler M, Konig A, El-Sheik M, Rinke A, Höffken H, Gress TM, Arnold R, Klose KJ, Wagner HJ. Selective internal radiotherapy with Yttrium-90 microspheres for hepatic metastatic neuroendocrine tumors: a prospective single center study. Digestion 2009;79:137-42.

54. Van der Zwan WA, Bodei L, Mueller-Brand J, de Herder WW, Kvols LK, Kwekkeboom DJ. GEPNETs update: Radionuclide therapy in neuroendocrine tumors. Eur J Endocrinol 2015;172:R1-8.

55. Stoeltzing O, Loss M, Huber E, Gross V, Eilles C, Mueller-Brand J, Schlitt HJ. Staged surgery with neoadjuvant 90Y-DOTATOC therapy for down-sizing synchronous bilobular hepatic metastases from a neuroendocrine pancreatic tumor. Langenbecks Arch Surg 2010;395:185-92.

56. Kaemmerer D, Prasad V, Daffner W, Hörsch D, Klöppel G, Hommann M, Baum RP. Neoadjuvant peptide receptor radionuclide therapy for an inoperable neuroendocrine pancreatic tumor. World $J$ Gastroenterol 2009;15:5867-70.

57. Sowa-Staszczak A, Pach D, Chrzan R, Trofimiuk M, Stefańska A, Tomaszuk M, Kołodziej M, Mikołajczak R, Pawlak D, HubalewskaDydejczyk A. Peptide receptor radionuclide therapy as a potential tool for neoadjuvant therapy in patients with inoperable neuroendocrine tumours (NETs). Eur J Nucl Med Mol Imaging 2011;38:1669-74.

58. Kwekkeboom DJ, de Herder WW, Kam BL, van Eijck CH, van Essen M, Kooij PP, Feelders RA, van Aken MO, Krenning EP. Treatment with the radiolabeled somatostatin analog $[177 \mathrm{Lu}-$ DOTA 0,Tyr3] octreotate: toxicity, efficacy, and survival. J Clin Oncol 2008;26:2124-30.

59. Strosberg J, Wolin E, Chasen B, Kulke M, Bushnell D, Caplin M, Baum RP, Mittra E, Hobday T, Hendifar A, Oberg K, Lopera Sierra M, Ruszniewski P, Kwekkeboom D; On behalf of the NETTER-1 study group. 177Lu-Dotatate significantly improves progressionfree survival in patients with midgut neuroendocrine tumours: results of the Phase III NETTER-1 trial. 18th ECCO-40th ESMO- European Cancer Congress 2015, 27 September 2015, abs 6LBA, Vienna.

60. Kong G, Johnston V, Ramdave S, Lau E, Rischin D, Hicks RJ. High administered activity In-111 octreotide therapy with concomitant radiosensitizing 5FU chemotherapy for treatment of neuroendocrine tumors: preliminary experience. Cancer Biother Radiopharm 2009;24:527-33.

61. Bison SM, Pool SE, Koelewijn SJ, van der Graaf LM, Groen HC, Melis M, de Jong M. Peptide receptor radionuclide therapy (PRRT) with [(177)Lu-DOTA(0),Tyr(3)]octreotate in combination with RAD001 treatment: further investigations on tumor metastasis and response in the rat pancreatic CA20948 tumor model. EJNMMI Res 2014;4:21.

62. Oberg K. Interferons in the management of neuroendocrine tumors and their possible mechanism of action. Yale J Biol and Med 1992;65:519-29.

63. Frank M, Klose KJ, Wied M, Ishaque N, Schade-Brittinger C, Arnold R. Combination therapy with octreotide and alpha-interferon: effect on tumor growth in metastatic endocrine gastroenteropancreatic tumors. Am J Gastroenterol 1999;94:1381-7.

64. Faiss S, Pape UF, Böhmig M, Dörffel Y, Mansmann U, Golder W, Riecken EO, Wiedenmann B; International Lanreotide and Interferon Alfa Study Group. Prospective, randomized, multicenter trial on the antiproliferative effect of lanreotide, interferon alfa, and their combination for therapy of metastatic neuroendocrine gastroenteropancreatic tumors -- The International Lanreotide and Interferon Alfa Study Group. J Clin Oncol 2003;21:2689-96.

65. Arnold R, Rinke A, Klose K, Müller HH, Wied M, Zamzow K, Schmidt C, Schade-Brittinger C, Barth P, Moll R Koller M, Unterhalt M, Hiddemann W, Schmidt-Lauber M, Pavel M, Arnold CN. Octreotide versus octreotide plus interferon-alpha in endocrine gastroenteropancreatic tumors: a randomized trial. Clin
Gastroenterol Hepatol 2005;3:761-71.

66. Modlin IM, Oberg K, Chung DC, Jensen RT, de Herder WW, Thakker RV, Caplin M, Delle Fave G, Kaltsas GA, Krenning EP, Moss SF, Nilsson O, Rindi G, Salazar R, Ruszniewski P, Sundin A. Gastroenteropancreatic neuroendocrine tumours. Lancet Oncol 2008;9:61-72.

67. Andreyev H, Scott-Mackie P, Cunningham D, Nicolson V, Norman AR, Badve SS, Iveson A, Nicolson MC. Phase II study of continuous infusion fluorouracil and interferon alfa- $2 \mathrm{~b}$ in the palliation of malignant neuroendocrine tumors. J Clin Oncol 1995;13:1486-92.

68. Eriksson B, Skogseid B, Lundqvist G, Wide L, Wilander E, Oberg $\mathrm{K}$. Medical treatment and long-term survival in a prospective study of 84 patients with endocrine pancreatic tumors. Cancer 1990;65:1883-90.

69. Dahan, L, Bonnetain F, Rougier P, Raoul JL, Gamelin E, Etienne PL, Cadiot G, Mitry E, Smith D, Cvitkovic F, Coudert B, Ricard F, Bedenne L, Seitz JF; Fédération Francophone de Cancérologie Digestive (FFCD); Digestive Tumors Group of the Fédération Nationale des Centres de Lutte Contre le Cancer (FNCLCC). Phase III trial of chemotherapy using 5-fluorouracil and streptozotocin compared with interferon alpha for advanced carcinoid tumors: FNCLCC-FFCD 9710. Endocr Relat Cancer 2009;16:1351-61.

70. Mirvis E, Mandair D, Garcia-Hernandez J, Mohmaduvesh M, Toumpanakis C, Caplin M. Role of interferon-alpha in patients with neuroendocrine tumors: a retrospective study. Anticancer Res 2014;34:6601-7.

71. Dogliotti L, Tampellini M, Stivanello M, Gorzegno G, Fabiani L. The clinical management of neuroendocrine tumors with long-acting repeatable (LAR) octreotide: comparison with standard subcutaneous octreotide therapy. Ann Oncol 2001;12 Suppl 2:S105-9.

72. Rinke A, Müller HH, Schade, Brittinger C, Klose KJ, Barth P, Wied M, Mayer C, Aminossadati B, Pape UF, Bläker M, Harder J, Arnold C, Gress T, Arnold R; PROMID Study Group. Placebocontrolled, double-blind, prospective, randomized study on the effect of octreotide LAR in the control of tumor growth in patients with metastatic neuroendocrine midgut tumors: a report from the PROMID Study Group. J Clin Oncol 2009;27:4656-63.

73. Caplin ME, Pavel M, Ćwikła JB, Phan AT, Raderer M, Sedláčková E, Cadiot G, Wolin EM, Capdevila J, Wall L, Rindi G, Langley A, Martinez S, Blumberg J, Ruszniewski P; CLARINET Investigators; Lanreotide in metastic enteropancreatic neuroendocrine tumors. $N$ Engl J Med 2014;371:224-33.

74. Cives M, Kunz PL, Morse B, Coppola D, Schell MJ, Campos T, Nguyen PT, Nandoskar P, Khandelwal V, Strosberg JR. Phase II clinical trial of pasireotide long-acting repeatable in patients with metastatic neuroendocrine tumors. Endocr Relat Cancer 2015;22:1-9.

75. Alonso-Gordoa T, Capdevila J, Grande E. GEP-NETs update: Biotherapy for neuroendocrine tumours. Eur $J$ Endocrinol 2015;172:R31-46.

76. Yao JC, Shah MH, Ito T, Bohas CL, Wolin EM, Van Cutsem E, Hobday TJ, Okusaka T, Capdevila J, de Vries EG, Tomassetti P, Pavel ME, Hoosen S, Haas T, Lincy J, Lebwohl D, Öberg K; RAD001 in Advanced Neuroendocrine Tumors, Third Trial (RADIANT-3) Study Group. Everolimus for advanced pancreatic neuroendocrine tumors. N Engl J Med 2011;364:514-23.

77. Briest F, Grabowski P. PI3K-AKT-mTOR-signaling and beyond: the complex network in gastroentero-pancreatic neuroendocrine neoplasms. Theranostics 2014;4:336-65.

78. Capdevila J, Salazar R, Halperin I, Abad A, Yao JC. Innovations therapy: mammalian target of rapamycin (mTOR) inhibitors for the treatment of neuroendocrine tumors. Cancer Metastasis Rev 2011;30 Suppl 1:27-34.

79. Chambers J, Reed N, Mansoor W, Ross P, Grossman A. Phase-3 randomized trial of everolimus (RAD001) vs. placebo in advanced pancreatic NET (RADIANT-3). Regul Pept 2010;164:6-7.

80. Pavel ME, Hainsworth JD, Baudin E, Peeters M, Hörsch D, Winkler 
RE, Klimovsky J, Lebwohl D, Jehl V, Wolin EM, Oberg K, Van Cutsem E, Yao JC; RADIANT-2 Study Group. Everolimus plus octreotide long-acting repeatable for the treatment of advanced neuroendocrine tumours associated with carcinoid syndrome (RADIANT-2): a randomised, placebo-controlled, phase 3 study. Lancet 2011;378:2005-12.

81. Yao JC, Fazio N, Singh S, Buzzoni R, Carnaghi C, Wolin E, Tomasek J, Raderer M, Lahner H, Voi M, Pacaud LB, Rouyrre N, Sachs C, Valle JW, Fave GD, Van Cutsem E, Tesselaar M, Shimada Y, Oh DY, Strosberg J, Kulke MH, Pavel ME; RAD001 in Advanced Neuroendocrine Tumours, Fourth Trial (RADIANT-4) Study Group. Everolimus for the treatment of advanced, nonfunctional neuroendocrine tumours of the lung or gastrointestinal tract (RADIANT-4): a randomised, placebo-controlled, phase 3 study. Lancet 2016;387:968-77.

82. Raymond E, Dahan L Raoul JL, Bang YJ, Borbath I, LombardBohas C, Valle J, Metrakos P, Smith D, Vinik A, Chen JS, Hörsch D, Hammel P, Wiedenmann B, Van Cutsem E, Patyna S, Lu DR, Blanckmeister C, Chao R, Ruszniewski P. Sunitinib malate for the treatment of pancreatic neuroendocrine tumors. $N$ Engl J Med 2011;364:501-13.

83. Motzer RJ, Hutson TE, Tomczak P, Michaelson MD, Bukowski RM, Oudard S, Negrier S, Szczylik C, Pili R, Bjarnason GA, Garciadel-Muro X, Sosman JA, Solska E, Wilding G, Thompson JA, Kim ST, Chen I, Huang X, Figlin RA. Overall survival and updated results for sunitinib compared with interferon alfa in patients with metastatic renal cell carcinoma. J Clin Oncol 2009;27:3584-90.

84. Oxboel J, Binderup T, Knigge U, Kjaer A. Quantitative geneexpression of the tumor angiogenesis markers vascular endothelial growth factor, integrin alphaV and integrin beta3 in human neuroendocrine tumors. Oncol Rep 2009;21:769-75.

85. Yao JC, Phan A, Hoff PM, Chen HX, Charnsangavej C, Yeung SC, Hess K, Ng C, Abbruzzese JL, Ajani JA. Targeting vascular endothelial growth factor in advanced carcinoid tumor: a random assignment phase II study of depot octreotide with bevacizumab and pegylated interferon alpha-2b. J Clin Oncol 2008;26:1316-23.

86. Kulke MH, Niedzwiecki D, Foster NR, Fruth B, Kunz PL, Kennecke HF, Wolin EM, Venook AP. Randomized phase II Study of Everolimus versus Everolimus plus Bevacizumab in patients with locally advanced or metastatric panxcreatic neuroencocrine tumors CALG80701 (Alliance). Proceedings of 2015 ASCO Annual meeting. J Clin Oncol 2015;33:15S, abs 4005.

87. Mayo SC, Herman JM, Cosgrove D, Bhagat N, Kamel I, Geschwind JF, Pawlik TM. Emerging approaches in the management of patients with neuroendocrine liver metastasis: role of liver-directed and systemic therapies. J Am Coll Surg 2013;216:123-34.

88. Ekeblad S, Sundin A, Janson ET, Welin S, Granberg D, Kindmark H, Dunder K, Kozlovacki G, Orlefors H, Sigurd M, Oberg K, Eriksson B, Skogseid B. Temozolomide as monotherapy is effective in treatment of advanced malignant neuroendocrine tumors. Clin Cancer Res 2007; 13:2986-91.

89. Kouvaraki MA, Ajani JA, Hoff P, Wolff R, Evans DB, Lozano R, Yao JC. Fluorouracil, doxorubicin, and streptozocin in the treatment of patients with locally advanced and metastatic pancreatic endocrine carcinomas. J Clin Oncol 2004;22:4762-71.

90. Strosberg JR, Fine RL, Choi J, Nasir A, Coppola D, Chen DT, Helm J, Kvols L. First-line chemotherapy with capecitabine and temozolomide in patients with metastatic pancreatic endocrine carcinomas. Cancer 2011;117:268-75.

91. Berruti A, Fazio N, Ferrero A, Brizzi MP, Volante M, Nobili E, Tozzi L, Bodei L, Torta M, D’Avolio A, Priola AM, Birocco N, Amoroso V, Biasco G, Papotti M, Dogliotti L. Bevacizumab plus octreotide and metronomic capecitabine in patients with metastatic well-tomoderately differentiated neuroendocrine tumors: the xelbevoct study. BMC Cancer 2014;14:184.

92. Walter T, Bruneton D, Cassier PA, Hervieu V, Pilleul F, Scoazec JY, Chayvialle JA, Lombard-Bohas C. Evaluation of the combination 5 -fluorouracil, dacarbazine, and epirubicin in patients with advanced well-differentiated neuroendocrine tumors. Clin Colorectal Cancer 2010;9:248-54. 